\title{
Application of multiple-point geostatistics on modelling groundwater flow and transport in a cross-bedded aquifer (Belgium)
}

\author{
Marijke Huysmans • Alain Dassargues
}

\begin{abstract}
Sedimentological processes often result in complex three-dimensional subsurface heterogeneity of hydrogeological parameter values. Variogram-based stochastic approaches are often not able to describe heterogeneity in such complex geological environments. This work shows how multiple-point geostatistics can be applied in a realistic hydrogeological application to determine the impact of complex geological heterogeneity on groundwater flow and transport. The approach is applied to a real aquifer in Belgium that exhibits a complex sedimentary heterogeneity and anisotropy. A training image is constructed based on geological and hydrogeological field data. Multiple-point statistics are borrowed from this training image to simulate hydrofacies occurrence, while intrafacies permeability variability is simulated using conventional variogram-based geostatistical methods. The simulated hydraulic conductivity realizations are used as input to a groundwater flow and transport model to investigate the effect of small-scale sedimentary heterogeneity on contaminant plume migration. Results show that small-scale sedimentary heterogeneity has a significant effect on contaminant transport in the studied aquifer. The uncertainty on the spatial facies distribution and intrafacies hydraulic conductivity distribution results in a significant uncertainty on the calculated concentration distribution. Comparison with standard variogram-based techniques shows that multiple-point geostatistics allow better reproduction of irregularly shaped low-permeability clay drapes that influence solute transport.
\end{abstract}

Received: 9 July 2008 / Accepted: 8 June 2009

(C) Springer-Verlag 2009

M. Huysmans $(\bullet) \cdot A$. Dassargues

Department of Earth and Environmental Sciences,

Katholieke Universiteit Leuven, Applied Geology and Mineralogy, Celestijnenlaan 200 E, 3001, Heverlee, Belgium

e-mail: marijke.huysmans@ees.kuleuven.be

Tel.: +32-16-326449

Fax: +32-16-322980

\section{A. Dassargues}

Department of Architecture, Geology, Environment, and Civil Engineering (ArGEnCo),

Université de Liège, Hydrogeology and Environmental Geology, B.52/3 Sart-Tilman, 4000, Liège, Belgium
Keywords Heterogeneity · Multiple-point geostatistics · Groundwater flow · Solute transport · Belgium

\section{Introduction}

Sedimentological and erosional processes often result in a complex three-dimensional subsurface architecture of sedimentary structures and facies types. Such complex sedimentological heterogeneity may induce a highly heterogeneous spatial distribution of hydrogeological parameter values in porous media at different scales (Klingbeil et al. 1999) and may consequently greatly influence subsurface fluid flow and solute migration (Koltermann and Gorelick 1996). Therefore, groundwater flow and transport models rely on a detailed description of the hydraulic properties of the subsurface. Because of the limited access to the relevant hydraulic properties, deterministic models often fall short in characterizing the subsurface heterogeneity and its inherent uncertainty. In recent decades, numerous stochastic approaches have been developed to overcome this problem. Most of these methods employ a variogram to characterize the heterogeneity of the hydraulic parameters (Goovaerts 1997; Deutsch and Journel 1998; Caers 2005). Variograms are calculated based on two-point correlations only and therefore have some important limitations. Variograms are not able to describe realistic heterogeneity in complex geological environments. Complex geological patterns including sedimentary structures, multi-facies deposits, structures with large connectivity, curvi-linear structures, etc. cannot be characterized using only two-point statistics (Koltermann and Gorelick 1996; Fogg et al. 1998; Journel and Zhang 2006). Moreover, variograms, as a limited and parsimonious mathematical tool, cannot take full advantage of the possibly rich amount of geological information from outcrops (Caers and Zhang 2004).

Multiple-point geostatistics aims to overcome the limitations of the variogram. The premise of multiplepoint geostatistics is to move beyond two-point correlations between variables and to obtain (cross) correlation moments at three or more locations at a time (Guardiano and Srivastava 1993; Strebelle and Journel 2001). Because of the limited direct well information from the subsurface, such statistical information cannot directly be obtained from samples. Instead, "training images" are used to characterize the patterns of geological heterogeneity. A 
training image is a conceptual explicit representation of the expected spatial distribution of hydraulic properties or facies types. The main idea is to borrow geological patterns from these training images and anchor them to the subsurface data domain. Such data may consist of well observation, geophysical and pumping or tracer tests. Construction of a suitable training image is one of the most critical and difficult steps of multiple-point geostatistics. The training image should be representative of the geological heterogeneity and must be large enough so that the essential features can be characterized by statistics defined on a limited point configuration ( $\mathrm{Hu}$ and Chugunova 2008). Moreover, training images are bound by the principles of stationarity and ergodicity (Caers and Zhang 2004).

Multiple-point geostatistics have recently been developed in the field of petroleum engineering (Strebelle 2000, 2002; Caers and Zhang 2004; Hu and Chugunova 2008); the method has been applied to several real-case studies (e.g., Strebelle et al. 2002). Applications of the method in the field of hydrogeology are very scarce. Feyen and Caers (2006) applied the method to a synthetic two-dimensional case to conclude that the method is potentially a powerful tool to improve groundwater flow and transport predictions. Ronayne et al. (2008) used multiple-point geostatistics in an inverse modelling approach to identify discrete geologic structures that produce anomalous hydraulic responses.

This study demonstrates how multiple-point geostatistics can be applied to determine the impact of complex geological heterogeneity on groundwater flow and transport in a real aquifer using field data. More precisely, multiple-point geostatistics are used in this study to investigate the effect of complex small-scale sedimentary heterogeneity on the short-term migration of a contaminant plume and its uncertainty. Since obtaining a suitable training image is one of the most critical steps of multiplepoint geostatistics, this paper shows how a training image can be constructed based on geological and hydrogeological field data. Furthermore, multiple-point geostatistics are compared with traditional variogram-based methods to determine the advantages of multiple-point geostatistics to predict transport of groundwater pollutants.

\section{Materials and method}

\section{Geological setting}

The aquifer of interest is the Brussels Sands formation, which is a major source of groundwater in Belgium. Approximately $29,000,000 \mathrm{~m}^{3}$ of groundwater per year is pumped from this aquifer. The Brussels Sands display a complex geological heterogeneity and anisotropy complicates pumping-test interpretation, groundwater modeling and prediction of pollutant transport. The Brussels Sands formation is an early middle-Eocene shallow marine sand deposit in central Belgium (Fig. 1). The formation consists of unconsolidated quartz sands with variable percentages of feldspars, silex, glauconite, carbonates and heavy minerals. The depositional environment of the Brussels Sands has been studied in detail by Houthuys (1990) based on field studies and descriptions of approximately 90 outcrops and hundreds of boreholes. The Brussels Sands are a tidal sandbar, deposited at the beginning of an important transgression at the southern border of the Eocene North Sea. Transverse sandbars that migrated to the north filled rapidly shifting channels. The tidal regime was strongly asymmetric and ebb-dominated with a NNE oriented main tidal flow. In a first depositional stage, large amounts of clastic sands mixed with coarse glauconite are deposited as thick cross-beds filling tide-parallel channels of a few kilometers wide and tens of meters deep. In a later depositional stage, the supply of glauconite ended and finer, carbonate-rich sands were deposited (Houthuys 1990). The Brussels Sands display several features and sedimentary structures typical for tidal deposits such as important grain size variations, cross-bedding, bottomsets, foresets, mud drapes and unidirectional reactivation surfaces.

\section{Field measurements}

An extensive field campaign was carried out consisting of observations of the sedimentary structures and 2,750 smallscale in situ measurements of air permeability in the Brussels Sands. The results and conclusions of this field campaign are summarized in this section. More details about this field campaign can be found in Huysmans et al. (2008).

A representative Brussels Sands outcrop (Bierbeek quarry near Leuven, Belgium) was mapped in detail with regard to the spatial distribution of sedimentary structures and lithologies. Geological sketches and digital photographs from all faces of the quarry were made. A visual distinction between sand-rich and clay-rich zones, hereafter called the sand facies and the silt facies respectively, was made in situ based on sediment characteristics. Figure 2 shows an interpreted photomosaic of one of the quarry walls, corrected for perspective distortion. Thickness and dip measurements of several sedimentary features were made at various locations in the quarry and analyzed statistically. Histograms of bottomset thicknesses, set thicknesses and lamination dipping angles measured during this measurement campaign and from Houthuys (1990) were calculated.

Additionally, a total of 2,750 air permeability measurements at $\mathrm{cm}$-scale were carried out in situ using the portable TinyPerm II distributed by New England Research (NER). Permeability measurements were taken by pressing the permeameter against the quarry face and depressing the plunger to withdraw air from a hemispherical-shaped sand volume with a radius of approximately $18 \mathrm{~mm}$. A microcontroller unit simultaneously monitored the syringe volume and the transient vacuum pulse created at the sample surface. This response is related to the air permeability of the sample, which can be determined by an equipment specific calibration curve. Measurements were taken on several rectangular regular grids with sizes between $40 \mathrm{~cm}$ and $1 \mathrm{~m}$ on different walls. The measurement spacing was adjusted to the lamina thickness so that the vertical and horizontal spacing was between 2 and $5 \mathrm{~cm}$.

Permeability histograms and variograms of the sand and silt facies were created (Figs. 3 and 4). Analysis of the spatial 


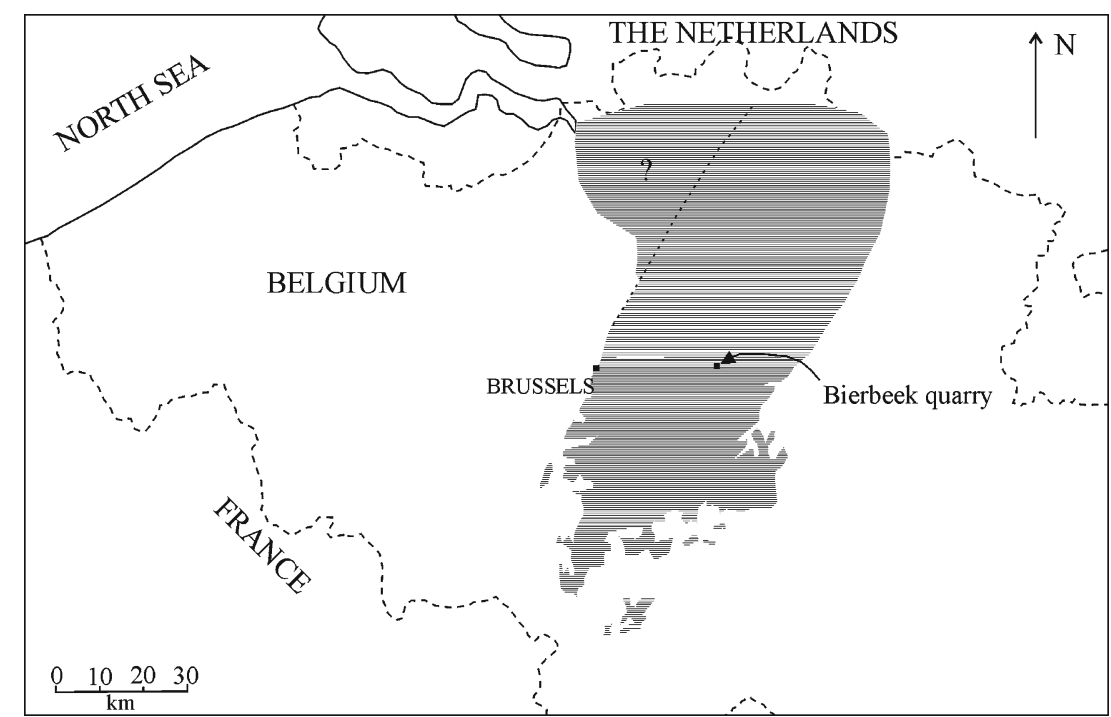

Fig. 1 Map of Belgium showing Brussels Sands outcrop and subcrop area (shaded part) and the location of the Bierbeek quarry (modified after Houthuys 1990)

distribution of sedimentary structures and permeability shows that silt facies consisting of clay-rich sedimentary features such as bottomsets and distinct mud drapes exhibit a different statistical and geostatistical permeability distribution compared to the sand facies (Table 1). Variogram map analysis of the air permeability data shows that permeability anisotropy in the cross-bedded lithofacies is dominated by the foreset-lamination orientation. These results show that small-scale sedimentary heterogeneity has a dominant control on the spatial distribution of the hydraulic properties and induces permeability heterogeneity and anisotropy (Huysmans et al. 2008). This paper investigates the effect of this permeability heterogeneity and anisotropy on groundwater flow and solute transport.

\section{Training image construction}

To demonstrate the need for "training images" in multiplepoint geostatistics, this section first briefly recalls the mathematical basis behind multiple-point geostatistics. The remainder of the section describes the training image construction process for this study.

Consider an attribute $S$, taking $J$ possible states $\left\{s_{j}, j=1 \ldots J\right\} . S$ can be a categorical property, for example facies, or a continuous value such as porosity or permeability, with its interval of variability discretized into $J$ classes. A data event $d_{n}$ of size $n$ centered at location $\mathrm{u}$ is constituted by (1) the data geometry defined by the $n$ vectors $\left\{\mathbf{h}_{\alpha}, \alpha=1 \ldots n\right\}$ and (2) the $n$ data values $\left\{s\left(\mathbf{u}+\mathbf{h}_{\alpha}\right), \alpha=1 \ldots n\right\}$. A data template $\tau_{n}$ comprises only the data geometry. The categorical transform of the variable $S$ at location u is defined as:

$I(\mathrm{u} ; j)=\left\{\begin{array}{l}0 \text { if } S(\mathbf{u})=s_{j} \\ 1 \text { if } S(\mathbf{u}) \neq s_{j}\end{array}\right.$

The multiple-point statistics are probabilities of occurrence of the data events $d_{n}=\left\{S\left(\mathbf{u}_{\alpha}\right)=s_{j, \alpha}, \alpha=1 \ldots n\right\}$, i.e. probabilities that the $n$ values $s\left(\mathbf{u}_{1}\right) \ldots s\left(\mathbf{u}_{j}\right)$ are jointly in the respective states $s_{j, 1} \ldots s_{j, n}$. For any data event $d_{n}$, that probability is also the expected value of the product of the $n$ corresponding indicator data:

$$
\begin{aligned}
\operatorname{Prob}\left\{d_{n}\right\} & =\operatorname{Prob}\left\{S\left(\mathbf{u}_{\alpha}\right)=s_{j, \alpha} ; \alpha=1 \ldots n\right\} \\
& =E\left[\prod_{\alpha=1}^{n} I\left(\mathbf{u}_{\alpha}, j_{\alpha}\right)\right]
\end{aligned}
$$

Such multiple-point statistics or probabilities cannot be inferred from sparse field data. Their inference requires a densely and regularly sampled training image depicting the expected patterns of geological heterogeneities. Training images do not need to carry any locally accurate information; they merely reflect a prior geological concept. Training images can be obtained from observations of outcrops, geological reconstructions and geophysical data, if necessary processed with Boolean simulation techniques (Strebelle and Journel 2001; Maharaja 2008).

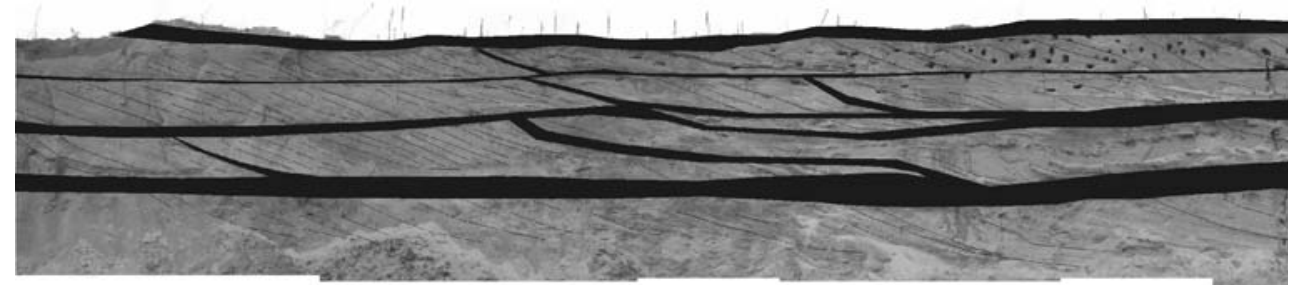

Fig. 2 Interpreted photomosaic of quarry wall showing the silt facies consisting of clay-rich bottomsets and distinct mud drapes in black. Height of quarry wall is approximately 4-5 m (Huysmans et al. 2008) 


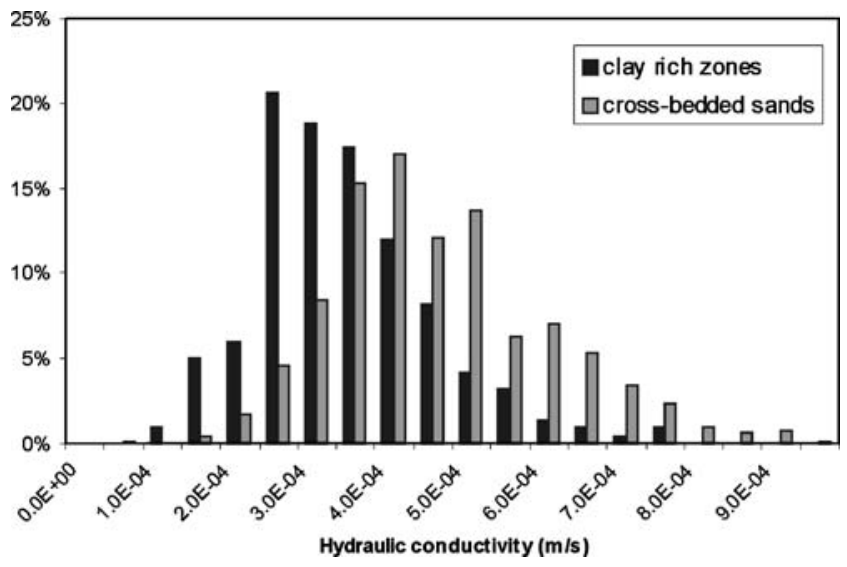

Fig. 3 Histogram of hydraulic conductivity $(\mathrm{m} / \mathrm{s})$ of sand-rich and clay-rich zones

In this study, training images were constructed based on observations of outcrops. Two-dimensional vertical training images of clay and sand occurrence in different orientations were constructed based on field photographs and observations of the geometry and dimensions of the sedimentary structures. The two-dimensional training images are composite sketches of smaller-scale photographs and field sketches conditioned by the histograms of set thicknesses, bottomset thicknesses and lamination angles. The training images were constructed by manually interpolating and extrapolating the sedimentary structures of smaller-scale photographs and field sketches, assuring that the structure dimensions on the training image obey the measured histograms of the sedimentary structure dimensions. The training image size is $30 \mathrm{~m} \times 30 \mathrm{~m}$. To capture the thin clay drapes, a small grid cell size of $0.05 \mathrm{~m} \times 0.05 \mathrm{~m}$ was adopted so that the training image consists of 360,000 grid nodes. Figure 5 shows the twodimensional training images in the $\mathrm{N} 40^{\circ} \mathrm{E}$ direction and the approximately perpendicular $\mathrm{N} 45^{\circ} \mathrm{W}$ direction. These training images show that the facies distribution in the $\mathrm{N} 40^{\circ} \mathrm{E}$ direction is rather complex while almost horizontal layering is observed in the perpendicular direction. Since the facies changes in the $\mathrm{N} 45^{\circ} \mathrm{W}$ direction are so limited

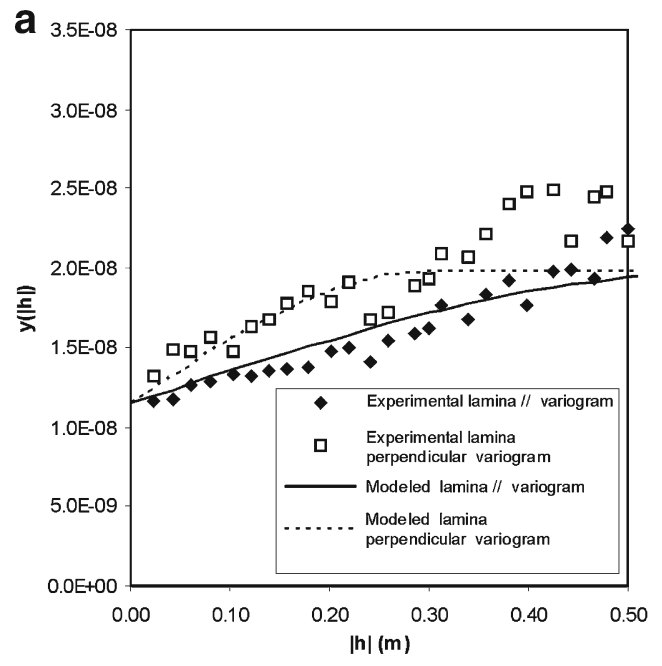

Fig. 4 Variograms of hydraulic conductivity $(\mathrm{m} / \mathrm{s})$ of a sand-rich and $\mathbf{b}$ clay-rich zones compared to the other direction, two-dimensional analyses have been carried out in the remainder of this paper only considering the training image shown in Fig. 5a. Consequently, the multiple-point geostatistical facies realizations, the intrafacies permeability realizations and the groundwater flow and transport model discussed in the following sections are all two-dimensional.

\section{Multiple-point geostatistical facies realizations}

Multiple-point statistics were borrowed from the training image to simulate multiple realizations of silt and sand facies occurrence using the single normal equation simulation (SNESIM) algorithm (Strebelle 2002) from SGeMS (Remy 2004). SNESIM is a pixel-based sequential simulation algorithm that obtains multiple-point statistics from the training image, exports it to the geostatistical numerical model and anchors it to the actual subsurface hard and soft data. For each location along a random path the data event $d_{n}$ consisting of the set of local data values and their spatial configuration was recorded. The training image was scanned for replicates that match this event to determine the local conditional probability that the unknown attribute $\mathrm{S}(\mathrm{u})$ takes any of the $J$ possible states given the data event $d_{n}$, as

$$
\begin{aligned}
& \operatorname{Prob}\left\{S(u)=s_{j} \mid d_{n}\right\} \\
& =\frac{\operatorname{Prob}\left\{S(\mathbf{u})=s_{j} \text { and } S\left(\mathbf{u}_{\alpha}\right)=s_{j, \alpha} ; \alpha=1 \ldots n\right\}}{\operatorname{Prob}\left\{S\left(\mathbf{u}_{\varepsilon}\right)=s_{j, \alpha} ; \alpha=1 \ldots n\right\}}
\end{aligned}
$$

The denominator can be inferred by counting the number of replicates of the conditioning data event found in the training image. The numerator can be obtained by counting the number of those replicates associated to a central value $S(\mathbf{u})$ equal to $s_{k}$. A maximum data search template is defined to limit the geometric extent of those data events. SNESIM requires reasonable CPU (central processing unit) demands by scanning the training image prior to simulation and storing the conditional probabilities in a dynamic data structure, called the search tree. The

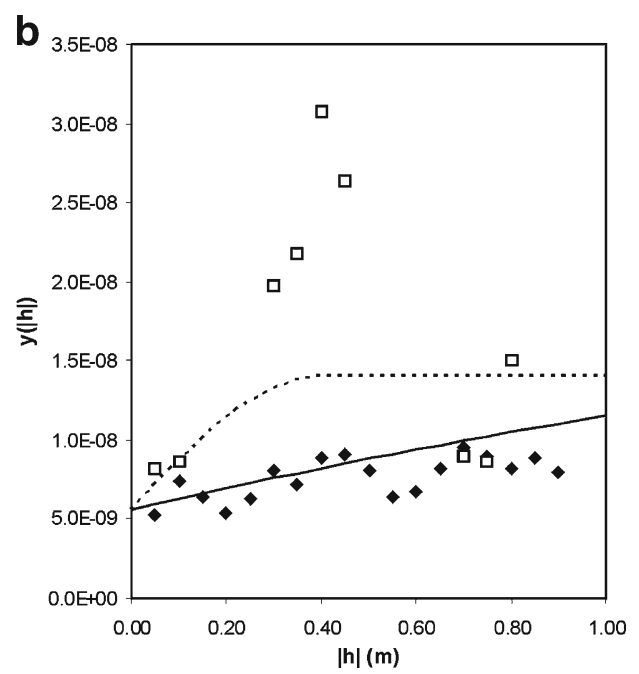


Table 1 Statistical and variogram parameters of hydraulic conductivity $(K)$ for the sand and silt facies (values from Huysmans et al. 2008)

\begin{tabular}{lll}
\hline & $\begin{array}{l}\text { Sand } \\
\text { facies }\end{array}$ & Silt facies \\
\hline Mean $K(\mathrm{~m} / \mathrm{s})$ & $4.35 \mathrm{e}-4$ & $3.12 \mathrm{e}-4$ \\
Geometric mean $K(\mathrm{~m} / \mathrm{s})$ & $4.12 \mathrm{e}-4$ & $3.05 \mathrm{e}-4$ \\
Variance $K(\mathrm{~m} / \mathrm{s})^{2}$ & $1.98 \mathrm{e}-8$ & $1.40 \mathrm{e}-8$ \\
Variance $\log _{10} K$ & 0.021 & 0.029 \\
Variogram type $K$ & Spherical & Spherical \\
Nugget $(\mathrm{m} / \mathrm{s})^{2}$ & $1.15 \mathrm{e}-8$ & $5.65 \mathrm{e}-9$ \\
Sill $(\mathrm{m} / \mathrm{s})^{2}$ & $8.29 \mathrm{e}-9$ & $8.34 \mathrm{e}-9$ \\
Dip angle of major axis of & $26^{\circ}$ & $0^{\circ}$ \\
$\quad$ anisotropy & 0.6 & (horizontal) \\
Lamina parallel range $(\mathrm{m})$ & 0.3 & 0.4 \\
Lamina perpendicular range $(\mathrm{m})$ & & \\
\hline
\end{tabular}

theory and algorithm behind SNESIM are described in Strebelle (2002). Descriptions of standard SNESIM parameters are in Liu (2006). A description of the subgrid approach which is an option to reduce memory and CPU time demand by (1) simulating intermediary subgrids within each grid in the multiple-grid approach and by (2) using data templates that are preferentially constituted by previously simulated nodes can be found in Strebelle (2003). A description of the post-processing algorithm used in SGeMS to improve reproduction of training patterns by re-simulating inconsistent node values can be found in Strebelle and Remy (2005).

The computation time and pattern reproduction quality of SNESIM realizations are strongly dependent on the input parameters selection (Liu 2006). In this particular case, the input parameters selection was complicated by the nature of the heterogeneity. The combination of thin clay drapes and relatively large structures results in a large training image size with a small grid cell size. This requires a large template size and thus a large CPU and RAM (random access memory) demand. To optimally choose the input parameter values, a sensitivity analysis of the input parameters to pattern reproduction and computation time was carried out. The simulation grid is $10 \mathrm{~m} \times 10 \mathrm{~m}$ and

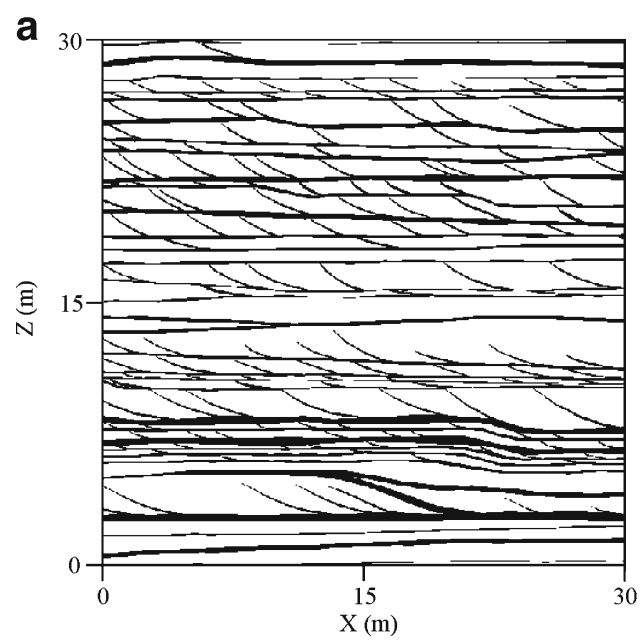

Fig. 5 Vertical two-dimensional training image of $30 \mathrm{~m} \times 30 \mathrm{~m}$ in a $\mathrm{N} 40^{\circ} \mathrm{E}$ direction and $\mathbf{b} \mathrm{N} 45^{\circ} \mathrm{W}$ direction (white refers to sand facies, black refers to silt facies)

\section{Intrafacies permeability simulation}

Intrafacies permeability variability within the sand and silt facies was simulated using conventional variogram-based geostatistical methods based on histograms and variograms obtained from the in situ air permeability measurements. The simulation algorithm used in this study is a direct sequential simulation with histogram reproduction (Oz et al. 2003). This approach creates realizations that reproduce (1) the local point and block data in the original data units, (2) the mean, variance and variogram of the variable and (3) the histogram of the variable $(\mathrm{Oz}$ et al. 2003). The input statistics and variogram parameters of permeability for both facies are presented in Table 1. Simulation was performed separately for each facies after which the simulated sand and silt facies realizations are assembled. For the sand facies, the dip angle of the major axis of anisotropy was assumed to be $26^{\circ}$; for the silt facies it was assumed to be $0^{\circ}$ (horizontal). Air perme-

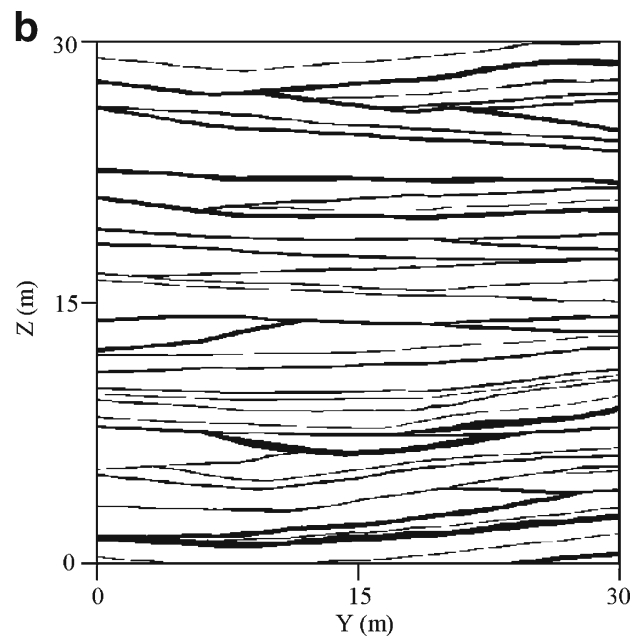



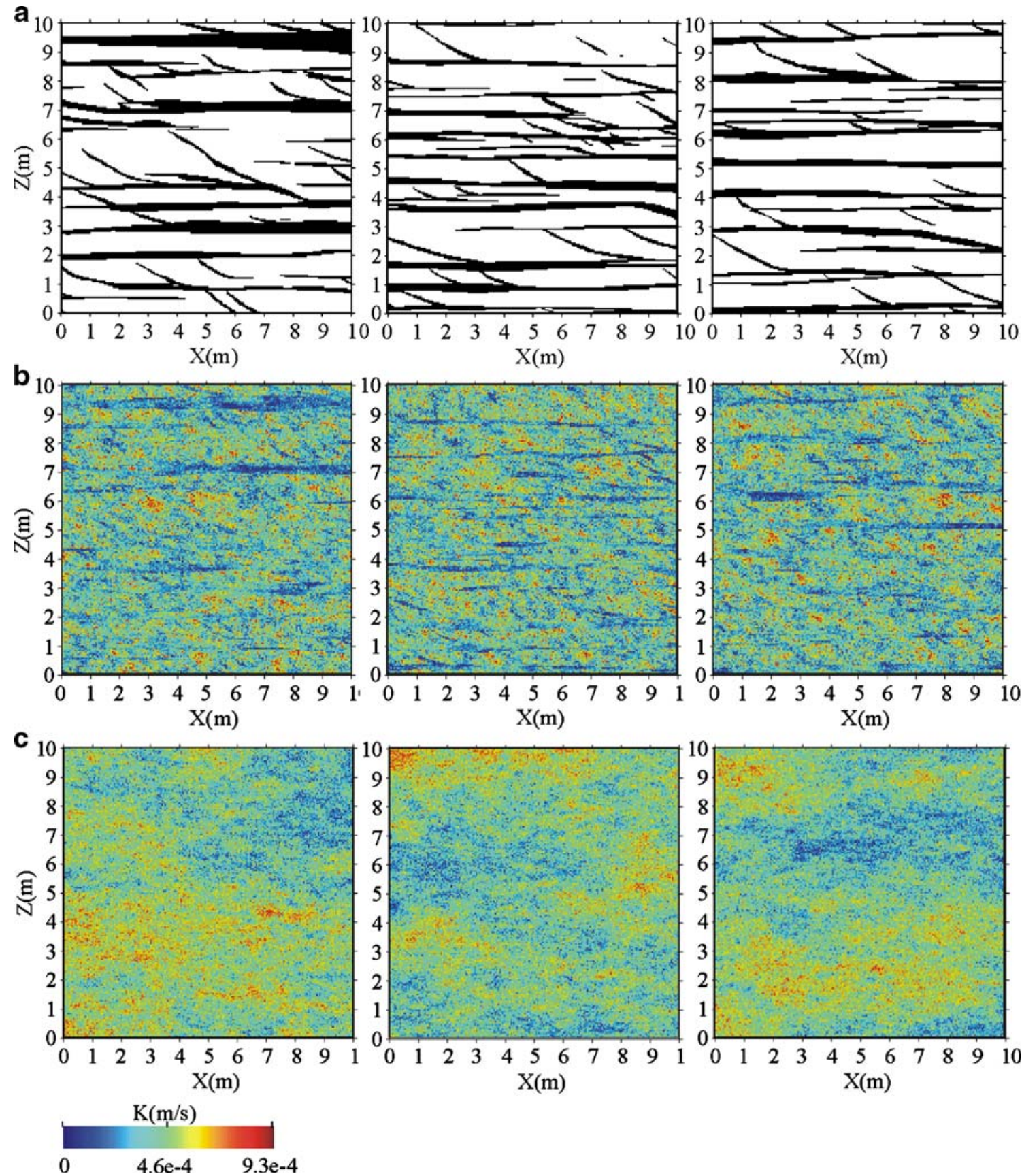

Fig. 6 a Example SNESIM facies realizations (white refers to sand facies, black refers to silt facies); b corresponding hydraulic conductivity $K(\mathrm{~m} / \mathrm{s})$ realizations; c SGSIM hydraulic conductivity $K(\mathrm{~m} / \mathrm{s})$ realizations

ability realizations were converted into hydraulic conductivity realizations to serve as input to a local groundwater flow model using the unique relationship between permeability $k$ and saturated hydraulic conductivity $K$.

In this way, intrafacies hydraulic conductivity of the 150 facies realizations was simulated. Figure $6 \mathrm{~b}$ shows the hydraulic conductivity realizations of the facies realizations of Fig. 6a. The silt facies are visible in the hydraulic conductivity realizations as areas with lower hydraulic conductivity but there are no continuous flow barriers since the sand and silt permeability distributions are overlapping.
For comparison, hydraulic conductivity was also simulated using the standard variogram-based algorithm SGSIM from SGeMS (Remy 2004) without accounting for the facies. The variogram used is the average variogram of the hydraulic conductivity simulations (Fig. 6b) so that differences in results between both techniques can not be attributed to different variograms.

\section{Groundwater flow and transport model}

The simulated hydraulic-conductivity realizations were used as input to a groundwater flow and transport model 
to investigate the effect of the small-scale sedimentary heterogeneity on early contaminant plume migration. The contaminant source is a hypothetical source. The location of this hypothetical source in the real world, and hence the location of the model, is not specified and could be anywhere in the Brussels Sands where the type of structures displayed in the training image occur. The model is a small-scale and short-term two-dimensional vertical model of $10 \mathrm{~m} \times 10 \mathrm{~m}$, discretized into very small grid cells of $5 \mathrm{~cm} \times 5 \mathrm{~cm}$ in order to represent the thin clay drapes present in the Brussels Sands. Constant head boundary conditions were applied to all boundaries so that the average horizontal gradient is $10 \mathrm{~m} / \mathrm{km}$ and the average vertical hydraulic gradient is $5 \mathrm{~m} / \mathrm{km}$, corresponding to observed gradients in the Brussels Sands. Porosity of the sand and silt facies were both assumed to be $30 \%$ since no facies specific porosity information is available. A hypothetical source of an inert contaminant was assumed at the surface at $x=2$ with an arbitrarily chosen flow rate of 1,000 1/day and an arbitrarily chosen source concentration of $1,000 \mathrm{mg} / \mathrm{l}$. Corresponding to the very small grid cell dimension, a very low longitudinal dispersivity value of $0.01 \mathrm{~m}$ was chosen. Transverse dispersivity was taken one order of magnitude smaller than longitudinal dispersivity (Zheng and Bennett 1995). Dispersivity values were assumed equal in both facies since no facies specific dispersivity information is available. The differential equations describing groundwater flow were solved by MODFLOW (McDonald and Harbaugh 1988), a block-centered finitedifference method based software package. Transport by advection and dispersion was simulated with MT3DMS (Zheng and Wang 1999), using the high-order finitevolume TVD solver. The Courant number used for determination of the time step size for transport calculations is 0.75 .

This groundwater flow and transport model was run 300 times for the 150 simulated hydraulic conductivity realizations using multiple-point geostatistical techniques and for the 150 standard SGSIM realizations. The distributions and uncertainty of the following three relevant output parameters were calculated and studied: (1) the maximum solute concentration after 3 days, (2) the maximum depth where a concentration of $1 \mathrm{mg} / \mathrm{l}$ is reached after 3 days and (3) the maximum horizontal distance to the source where a concentration of $1 \mathrm{mg} / \mathrm{l}$ is reached after 3 days. The convergence of the output parameter statistics in terms of the number of simulations was also studied in order to check whether 150 simulations are sufficient.

The results of the 150 SNESIM-based heterogeneous models were also compared with the results of a homogeneous model and with the results obtained by the standard variogram-based simulations. The comparison with the homogeneous model aims to study the effect of the small-scale sedimentary structures on contaminant plume migration in the Brussels Sands. The hydraulic conductivity of this homogeneous model was chosen as the value obtained from a pumping test in the coarse part of the Brussels Sands, i.e., $3.4 \times 10^{-4} \mathrm{~m} / \mathrm{s}$ (Bronders 1989).

\section{Results and discussion}

Figure 7 zooms in on the calculated contaminant plume for the three hydraulic conductivity realizations of Fig. 6 and shows simulated hydraulic head contours and contaminant concentrations for $t=3$ days. These figures show a different plume shape and extent and different maximum concentrations for the different hydraulic conductivity realizations. Figure 8 shows histograms of the three relevant output parameters defined in the previous section for the multiplepoint geostatistical SNESIM-based simulations and for the standard variogram-based SGSIM simulations. For the results obtained by multiple-point simulations, the maximum simulated solute concentration for $t=3$ days varies between 6.3 and $22.0 \mathrm{mg} / 1$ and shows a slightly skewed distribution with a mean of $10.7 \mathrm{mg} / \mathrm{l}$ and a standard deviation of $2.7 \mathrm{mg} / \mathrm{l}$. The maximum depth with a concentration of $1 \mathrm{mg} / 1$ for $t=3$ days varies between 1.3 and $1.9 \mathrm{~m}$ and shows a symmetric distribution with a mean of $1.6 \mathrm{~m}$ and a standard deviation of $0.1 \mathrm{~m}$. The maximum horizontal distance to the source with a concentration of $1 \mathrm{mg} / \mathrm{l}$ for $t=3$ days varies between 4.3 and $5.6 \mathrm{~m}$ and shows a slightly skewed distribution with a mean of $5.2 \mathrm{~m}$ and a standard deviation of $0.2 \mathrm{~m}$. The contaminant plumes of different realizations thus have significantly different characteristics. The largest maximum simulated solute concentration is more than three times larger than the smallest maximum simulated solute concentration. The largest maximum depth with $c=1 \mathrm{mg} / 1$ is almost $50 \%$ larger than the smallest maximum depth with $c=1 \mathrm{mg} / \mathrm{l}$ and the largest maximum horizontal distance with $c=1 \mathrm{mg} / \mathrm{l}$ is $30 \%$ larger than the smallest maximum horizontal distance with $c=1 \mathrm{mg} / \mathrm{l}$. These results show that the uncertainty on the spatial facies distribution and intrafacies hydraulic conductivity distribution results in a significant uncertainty on the calculated concentration distribution. Especially the maximum simulated concentration value can vary strongly among the different input hydraulic conductivity realizations. It is remarkable that the variation of the plume characteristics between different realizations is large even though the properties of both facies are rather similar (Table 1). This illustrates the importance of flow barriers on transport processes, even when these flow barriers are not completely continuous or impermeable. This variability would increase even more if the different porosity and dispersivity values would be assigned to the different facies.

Comparison with the results obtained by standard variogram-based simulations shows that both the averages and maxima of (1) the maximum depth with a concentration of $1 \mathrm{mg} / \mathrm{l}$ for $t=3$ days and (2) the maximum horizontal distance to the source with a concentration of $1 \mathrm{mg} / 1$ for $t=$ 3 days are larger for the variogram-based results. The contaminant plumes obtained by standard variogram-based simulations thus show a larger spread in horizontal and vertical direction than the contaminant plumes obtained by multiple-point geostatistical simulations. This is logical since multiple-point geostatistics allows better reproduction of the continuity of the low-permeability drapes that inhibit solute transport. The contaminant plumes are less hampered 

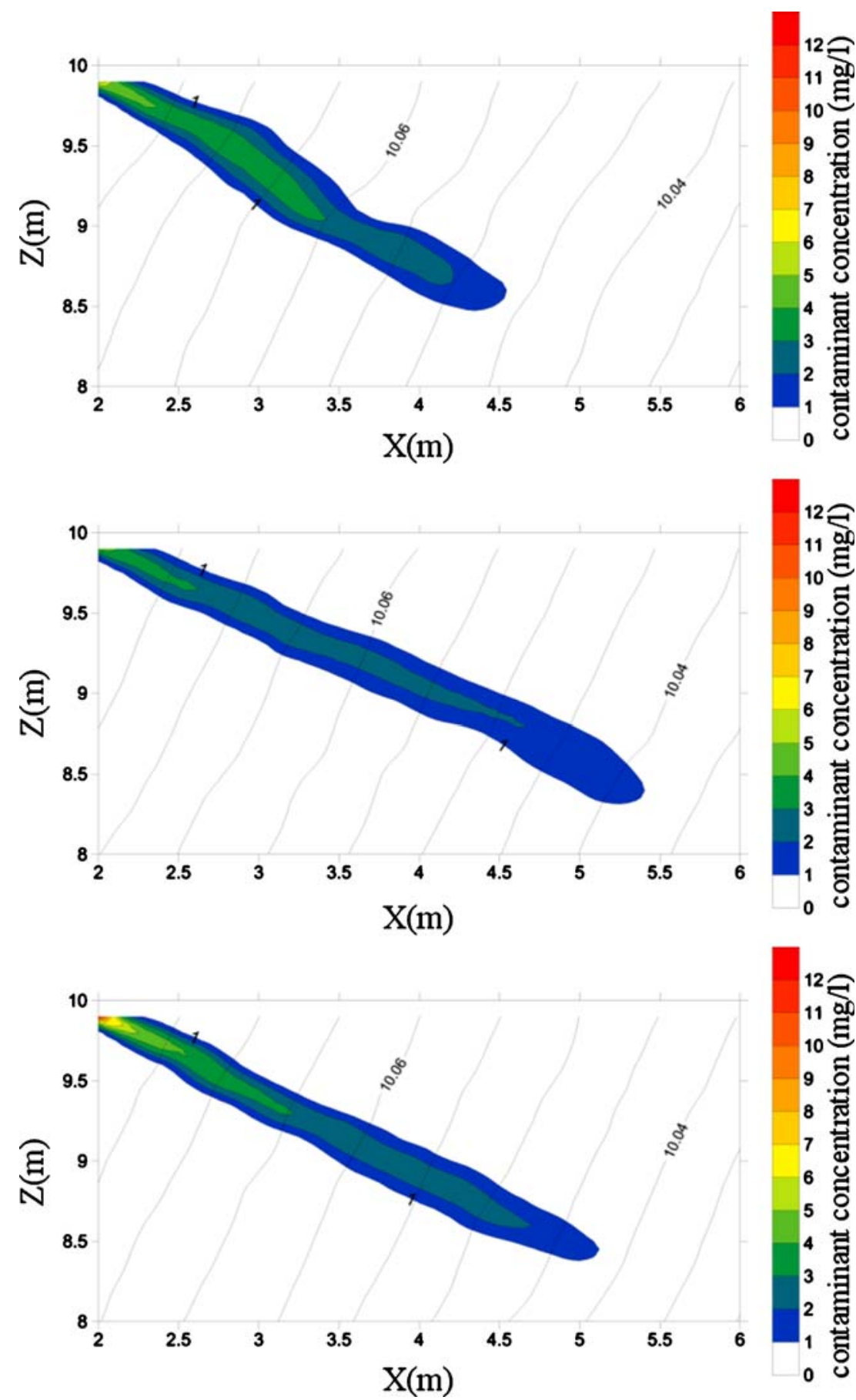

Fig. 7 Simulated hydraulic head contours and contaminant concentrations for $t=3$ days for the three realizations of Figure 6

by the low-permeability zones in the variogram-based hydraulic conductivity fields since these low-permeability zones are less continuous. Consequently, the contaminant plumes migrate on average further in horizontal and vertical directions in the variogram-based hydraulic conductivity fields compared to the multiple-point geostatistical hydraulic conductivity fields.

Figure 9 shows the convergence of the output parameters statistics as a function of the number of simulations. The output parameter averages vary strongly as long as less than 50 simulations are performed. After 50 simulations, the output parameter averages stabilize. This shows that 150 realizations are sufficient in this case.

The homogeneous model results in a maximum simulated solute concentration for $t=3$ days of $10.6 \mathrm{mg} / \mathrm{l}$, a maximum depth with a concentration of $1 \mathrm{mg} / 1$ for $t=3$ days of $1.6 \mathrm{~m}$ and a maximum horizontal distance to the source with a concentration of $1 \mathrm{mg} / 1$ for $t=3$ days of $4.9 \mathrm{~m}$. These values are close to the average output parameter values from the 150 heterogeneous 

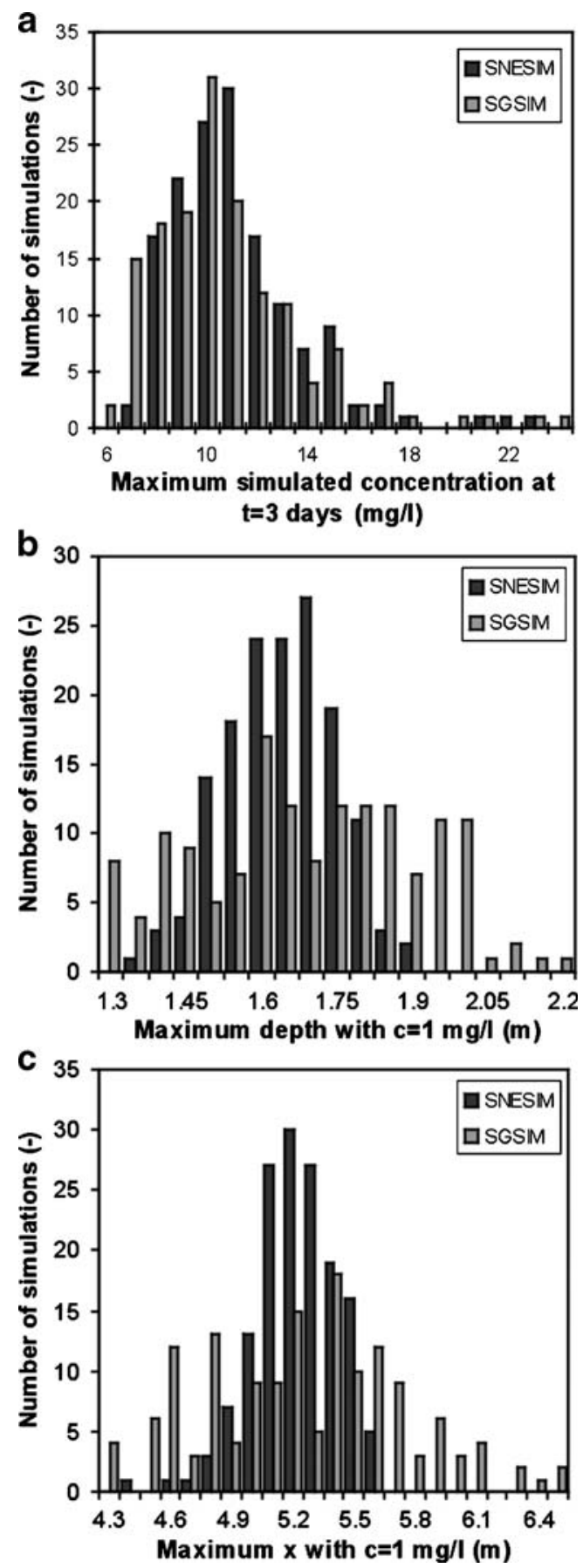

Fig. 8 Histograms of a maximum solute concentration after 3 days, $\mathbf{b}$ maximum depth where a concentration of $1 \mathrm{mg} / \mathrm{l}$ is reached after 3 days and $\mathbf{c}$ maximum horizontal distance to the source where a concentration of $1 \mathrm{mg} / \mathrm{l}$ is reached after 3 days

models. Many of the heterogeneous models result in contaminant plumes with significantly different characteristics compared to the homogeneous model. Using this homogeneous model instead of a heterogeneous model can lead to maximum errors of $108 \%$ for maximum simulated solute concentrations, almost $20 \%$ for maximum depth with $c=1 \mathrm{mg} / 1$ and $14 \%$ for maximum horizontal distance with $c=1 \mathrm{mg} / \mathrm{l}$. These results show that the small-scale sedimentary heteroge-

neity in the Brussels Sands has a significant effect on the calculated concentration distribution and that using a homogeneous model instead of a heterogeneous model can lead to significant error in the prediction of contaminant plume migration and concentrations.
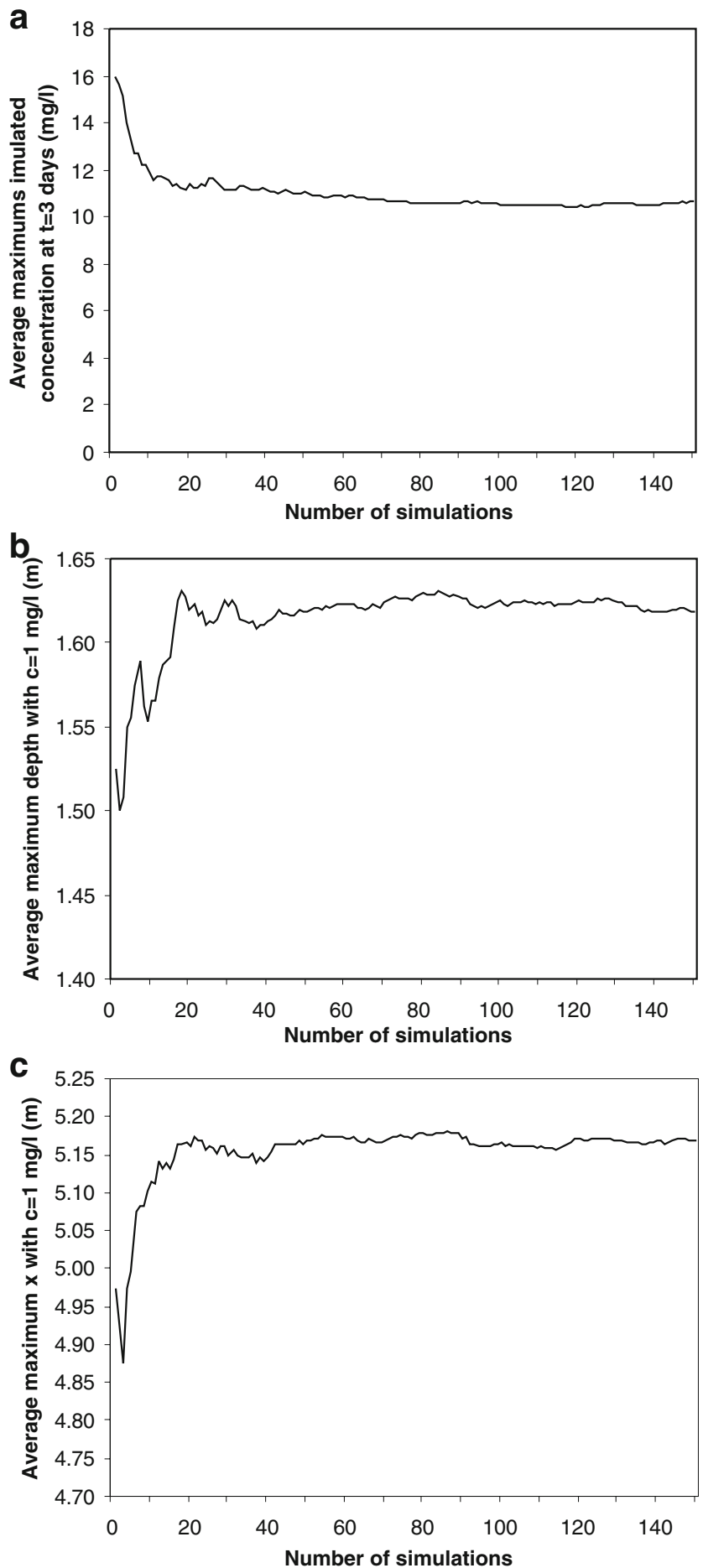

Fig. 9 Average of output parameters versus the number of simulations: a maximum solute concentration after 3 days, b maximum depth where a concentration of $1 \mathrm{mg} / \mathrm{l}$ is reached after 3 days and $\mathbf{c}$ maximum horizontal distance to the source where a concentration of $1 \mathrm{mg} / \mathrm{l}$ is reached after 3 days 


\section{Conclusions}

This study is one of the first studies that applies multiple-point geostatistics in the field of hydrogeology on a real aquifer. It demonstrates how a training image can be constructed based on geological and hydrogeological field data and how multiple-point geostatistics can be applied to determine the impact of complex geological heterogeneity on groundwater flow and transport in a real aquifer. Application of the proposed approach of a hypothetical contaminant case in the Brussels Sands shows that the uncertainty on the spatial facies distribution and intrafacies hydraulic conductivity distribution results in a significant uncertainty on the calculated concentration distribution. Comparison with standard variogram-based techniques shows that multiple-point geostatistics allows better reproduction of irregularly shaped low-permeability clay drapes that influence solute transport. The small-scale sedimentary heterogeneity in the Brussels Sands has a significant effect on the calculated concentration distribution and using a homogeneous model or a variogram-based model instead of a multiple-point geostatistical model can lead to significant error in the prediction of contaminant plume migration and concentrations.

By applying multiple-point geostatistics to a real aquifer, this work strengthens the conclusion of Feyen and Caers (2006) that multiple-point geostatistics is a very powerful tool to characterize subsurface heterogeneity for hydrogeological applications in a wide variety of complex geological settings. As many aquifers in the world display structures too complex for variogram-based methods and because simulation of connectivity of high and low permeability features is very important in hydrogeology (Kerrou et al. 2008), multiple-point geostatistics has many future applications in the field of hydrogeology. One of the most important challenges for multiple-point geostatistics lies in three-dimensional applications. Construction three-dimensional training images or performing 3D multiple-point simulations with two-dimensional training images remains an interesting research topic ( $\mathrm{Hu}$ and Chugunova 2008). Moreover, three-dimensional multiplepoint simulations often require a large CPU and RAM demand. The sensitivity of the model predictions to the training image and the compatibility between a training image and a specific data set ( $\mathrm{Hu}$ and Chugunova 2008) are also interesting topics for further research.

Acknowledgements The authors wish to acknowledge the Fund for Scientific Research, Flanders, for granting a Postdoctoral Fellowship to the first author.

\section{References}

Bronders J (1989) Bijdrage tot de geohydrologie van Midden België door middel van geostatistische analyse en een numeriek model [Contribution to the hydrogeology of Middle Belgium by means of geostatistical analysis and a numerical model]. PhD Thesis, Vrije Universiteit Brussel, Belgium
Caers J (2005) Petroleum geostatistics. An SPE Primer, Society of Petroleum Engineers, Richardson, TX, USA

Caers J, Zhang T (2004) Multiple-point geostatistics: a quantitative vehicle for integrating geologic analogs into multiple reservoir models. In: Integration of outcrop and modern analog data in reservoir models. AAPG Mem 80:383-394

Deutsch CV, Journel AG (1998) GSLIB, geostatistical software library and user's guide. Oxford University Press, New York

Feyen L, Caers J (2006) Quantifying geological uncertainty for flow and transport modeling in multi-modal heterogeneous formations. Adv Water Resour 29(6):912-929

Fogg GE, Noyes CD, Carle SF (1998) Geologically based model of heterogeneous hydraulic conductivity in an alluvial setting. Hydrogeol J 6(1):131-143

Goovaerts P (1997) Geostatistics for natural resources evaluation. Oxford University Press, Oxford

Guardiano F, Srivastava M (1993) Multivariate geostatistics: beyond bivariate moments. In: Soares A (ed) Geostatisticstroia. Kluwer, Dordrecht, The Netherlands, pp 133-144

Houthuys R (1990) Vergelijkende studie van de afzettingsstruktuur van getijdenzanden uit het Eoceen en van de huidige Vlaamse banken [Comparative study of the depositional structures of tidal sands from the Eocene and from the modern Flemish Banks]. Leuven University Press, Leuven, Belgium

$\mathrm{Hu}$ LY, Chugunova T (2008) Multiple-point geostatistics for modeling subsurface heterogeneity: a comprehensive review. Water Resour Res 44, W11413. doi:10.1029/2008WR006993

Huysmans M, Peeters L, Moermans G, Dassargues A (2008) Relating small-scale sedimentary structures and permeability in a cross-bedded aquifer. J Hydrol 361:41-51

Journel A, Zhang T (2006) The necessity of a multiple-point prior model. Math Geol 38(5):591-610

Kerrou J, Renard P, Franssen HJH, Lunati I (2008) Issues in characterizing heterogeneity and connectivity in non-multiGaussian media. Adv Water Resour 31(1):147-159

Koltermann CE, Gorelick S (1996) Heterogeneity in sedimentary deposits: a review of structure imitating, process-imitation, and descriptive approaches. Water Resour Res 32(9):2617-2658

Klingbeil R, Kleineidam S, Asprion U, Aigner T, Teutsch G (1999) Relating lithofacies to hydrofacies: outcrop-based hydrogeological characterisation of Quaternary gravel deposits. Sediment Geol 129(3-4):299-310

Liu Y (2006) Using the Snesim program for multiple-point statistical simulation. Comput Geosci 32(10):1544-1563

Maharaja A (2008) TiGenerator: object-based training image generator. Comput Geosci 34(12):1753-1761

McDonald MG, Harbaugh AW (1988) A modular three-dimensional finite-difference ground-water flow model. US Geol Surv OpenFile Rep 83-875

Oz B, Deutsch CV, Tran TT, Xie Y (2003) DSSIM-HR: a FORTRAN 90 program for direct sequential simulation with histogram reproduction. Comput Geosci 29(1):39-51

Remy N (2004) Geostatistical Earth Modeling Software: User's Manual. Stanford University, CA

Ronayne MJ, Gorelick SM, Caers J (2008) Identifying discrete geologic structures that produce anomalous hydraulic response: an inverse modeling approach. Water Resour Res. doi:10.1029/ 2007WR006635

Strebelle S (2000) Sequential simulation drawing structures from training images. $\mathrm{PhD}$ Thesis, Stanford University, USA

Strebelle S (2002) Conditional simulation of complex geological structures using multiple-point statistics. Math Geol 34:1-2

Strebelle S (2003) New multiple-point statistics simulation implementation to reduce memory and CPU-demand. Proceedings to the IAMG 2003, Portsmouth, UK, pp 7-12

Strebelle S, Journel A (2001) Reservoir modeling using multiplepoint statistics: SPE 71324 presented at the 2001 SPE Annual Technical Conference and Exhibition, New Orleans, 30 September-3 October 2001

Strebelle S, Remy N (2005) Post-processing of multiple-point geostatistical models to improve reproduction of training 
patterns. In: Leuangthong $\mathrm{O}$, Deutsch CV (eds) Geostatistics Banff 2004, vol 2. Springer, Dordrecht, The Netherlands, pp 979-987

Strebelle S, Payrazyan K, Caers J (2002) Modeling of a deepwater turbidite reservoir conditional to seismic data using multiplepoint geostatistics. Society of Petroleum Engineers (SPE) Annual Conference and Technical Meeting, SPE 77429, San Antonio, TX, September 2001
Zheng C, Bennett GD (1995) Applied contaminant transport modeling: theory and practice. Wiley, New York

Zheng C, Wang PP (1999) MT3DMS, a modular three-dimensional multi-species transport model for simulation of advection, dispersion and chemical reactions of contaminants in groundwater systems. Documentation and user's guide. US Army Engineer Research and Development Center Contract Report SERDP-99-1, Vicksburg, MS 